\title{
A prospective study on changes in body composition and fat percentage during the first year of cancer treatment in children
}

\author{
Hye Ran Yang and Hyoung Soo Choi ${ }^{\text {S }}$ \\ Department of Pediatrics, Seoul National University Bundang Hospital, Seoul National University College of Medicine, 82 Gumi-ro 173 Beon-gil, Bundang-gu, Seongnam, \\ Gyeonggi 13620, Korea
}

BACKGROUNDS/OBJECTIVES: Cancer treatment may lead to significant body composition changes and affect growth and disease outcomes in pediatric cancer patients. This prospective study aimed to evaluate short- and long-term body compositions changes focused on body fat during the first year of cancer treatment in children.

SUBJECTS/METHODS: A prospective study was conducted in 30 pediatric cancer patients (19 hematologic malignancies and 11 solid tumors) and 30 age- and sex-matched healthy controls. Anthropometric measurements and body composition analysis using whole body dual energy X-ray absorptiometry were performed at baseline and 1, 6, and 12 month(s) of cancer treatment. Kruskal-Wallis tests, Wilcoxon paired $t$ tests, and generalized estimation equation (GEE) were applied for statistical analysis. RESULTS: At baseline, no differences in weight, height, body mass index, abdominal circumferences, body fat, and fat-free mass were observed between 30 controls and 30 pediatric cancer patients. Total fat mass $(P<0.001)$ and body fat percentage $(P=0.002)$ increased significantly during the first month, but no changes were observed from 1 to 12 months; however, no changes in the total mass were observed during the first year of cancer treatment. Meanwhile, the total fat-free mass decreased during the first month $(P=0.008)$ and recovered between 6 and 12 months of follow-up $(P<0.001)$. According to GEE analysis, there was a significant upward trend in body fat percentage during the first year, especially the first month, of cancer treatment in children with hematologic malignancies, but not in those with solid tumors.

CONCLUSIONS: Our results indicate that cancer treatment is related to significant body composition changes and rapid body fat gain, particularly during the first month after initiating cancer treatment, in children with hematologic malignancies. Therefore, individualized dietary strategies to prevent excessive fat gain are needed in pediatric cancer patients for better outcomes.

Nutrition Research and Practice 2019;13(3):214-221; https://doi.org/10.4162/nrp.2019.13.3.214; pISSN 1976-1457 elSSN 2005-6168

Keywords: Body composition, body fat distribution, neoplasms, child, absorptiometry

\section{INTRODUCTION}

Cancer treatment alters the nutritional status and body composition of growing children and adolescents, and these changes can affect physical growth, disease course, and clinical outcomes in pediatric cancer patients [1,2].

Because poor nutritional status was previously reported to be related to poor outcomes in children with cancer $[3,4]$, previous studies have focused mainly on undernutrition [5-7]. However, recently, not only undernutrition but also overnutrition that can cause excessive fat gain has also been proposed to affect the clinical outcome of cancer patients $[1,2]$. Butturini et al. [8] reported that survival rate was significantly reduced in 343 obese children out of 4,260 patient with acute lymphoblastic leukemia (ALL). Thus nutritional status and body composition of cancer patients need to be analyzed on the emphasis of body fat changes during cancer treatment $[1,2]$.

The application of dual energy X-ray absorptiometry (DXA) may be a more useful and accurate method than anthropometry to evaluate body composition, especially body fat mass and percentage, of cancer patients in both clinical practice and research $[9,10]$. However, most previous studies used only simple anthropometric measurements such as weight, height, body mass index (BMI), mid-upper arm circumference, and skinfold thickness and provided limited interpretations on changes in nutritional status and body composition in cancer patients $[3,6,7,9]$.

In addition, previous studies reporting significant changes in body composition of cancer patients were mostly adult studies, the results of which cannot be directly applied to childhood cancer patients $[9,11,12]$. According to these adult studies, the changes in body composition during the disease course tended to heterogeneous according to the type of underlying malignancies or cancer therapy regimens $[9,11,12]$.

To date, there are a few studies on body composition changes in pediatric cancer patients during cancer treatment, which

\footnotetext{
This research was supported by the Grant-in-Aid for Medical Science Research of Seoul National University Bundang Hospital (Grant No. 02-2012-064).

${ }^{\S}$ Corresponding Author: Hyoung Soo Choi, Tel. 82-31-787-7797, Fax. 82-31-787-4054, Email. choihs1786@snubh.org, choihs1786@gmail.com

Received: August 29, 2018, Revised: October 25, 2018, Accepted: January 21, 2019

This is an Open Access article distributed under the terms of the Creative Commons Attribution Non-Commercial License (http://creativecommons.org/licenses/by-nc/3.0/) which permits unrestricted non-commercial use, distribution, and reproduction in any medium, provided the original work is properly cited.
} 
have some limitations because only anthropometric measurements were used or body composition was measured not evaluating changes [9,13-15]. Furthermore, the type of underlying malignancies, in which treatment modalities are different, was considered in only one study [15].

Therefore, this prospective study aimed to evaluate short- and long-term changes of body compositions, particularly focused on body fat percentages, in pediatric cancer patients during the first year of cancer treatment using a DXA in addition to anthropometric measurement. And, we also aimed to compare the differences in body composition changes over time in different pediatric cancer groups (i.e., hematologic malignancies and solid tumors).

\section{SUBJECTS AND METHODS}

\section{Subjects}

Children with newly diagnosed cancers who were treated with chemotherapy between September 2012 and October 2014 were recruited in this prospective study for a longitudinal assessment of nutritional status and body compositions during the first year of cancer treatment as described in our previous study involving the same pediatric cancer cohort [16]. Patients with relapsed cancer were excluded from the study to eliminate the confounding effect of previous chemotherapy.

A total 30 ( 21 boys and 9 girls) pediatric cancer patients and 30 age and gender matched controls were enrolled. The control group included healthy individuals without cancer or any other underlying organic diseases selected from the outpatient department if they/their parents agreed to participate in the study.

Pediatric cancer patients were divided into the following two groups: hematologic malignancies $(n=19)$ and solid tumors ( =11) (Fig. 1). The 19 hematologic malignancies consisted of ALL $(n=8)$, acute myelogenous leukemia $(A M L ; n=4)$, lymphoma $(n=6)$, and Langerhans cell histiocytosis $(\mathrm{LCH} ; \mathrm{n}=1)$. Of the 11 solid tumors, there were 3 osteosarcomas, 2 brain tumors, 1 neuroblastoma, 1 Wilms tumor, 1 rhabdomyosarcoma, 1 Ewing sarcoma, 1 mesenchymal chondrosarcoma, and 1 solid pseudopapillary tumor of the pancreas.

\section{Cancer therapy protocols}

All cancer patients were treated based on pediatric cancer protocols consisting of multiple chemotherapeutic agents for 6-12 months before the final assessment at the outpatient clinic for pediatric cancer patients.

Patients with ALL, lymphoma, and $\mathrm{LCH}$ received $40-60 \mathrm{mg} / \mathrm{m}^{2}$ of prednisolone daily for 4-6 weeks of the induction period. The total cumulative dose of corticosteroid was $1.2-5.9 \mathrm{~g} / \mathrm{m}^{2}$ during 6-12 months of treatment. For solid tumor cases, including osteosarcoma, methotrexate $\left(48.0-84.0 \mathrm{~g} / \mathrm{m}^{2}\right)$ and ifosfamide $\left(9.0-63.0 \mathrm{~g} / \mathrm{m}^{2}\right)$ were administered. Busulfan- or melphalan-based conditioning regimens without total body irradiation were used in patients who underwent allogeneic or autologous hematopoietic stem cell transplantation.

\section{Anthropometry}

Body weight was determined to the nearest $0.1 \mathrm{~kg}$ using a calibrated digital scale, and height was measured to the nearest $0.1 \mathrm{~cm}$ on a standard height board. Abdominal circumference (AC) was measured twice using a tapeline at the maximum waist girth at umbilicus level in standing position [17].

BMI was calculated as weight $(\mathrm{kg})$ divided by height square $\left(\mathrm{m}^{2}\right)$. Weight, height, and BMI $z$ scores were calculated using the least mean squares method adjusted for age and gender based on the 2017 Korean National Growth Charts [18].

\section{Dual energy X-ray absorptiometry}

Body composition was measured using a whole body DXA scanner (Lunar Prodigy, General Electric Medical systems,

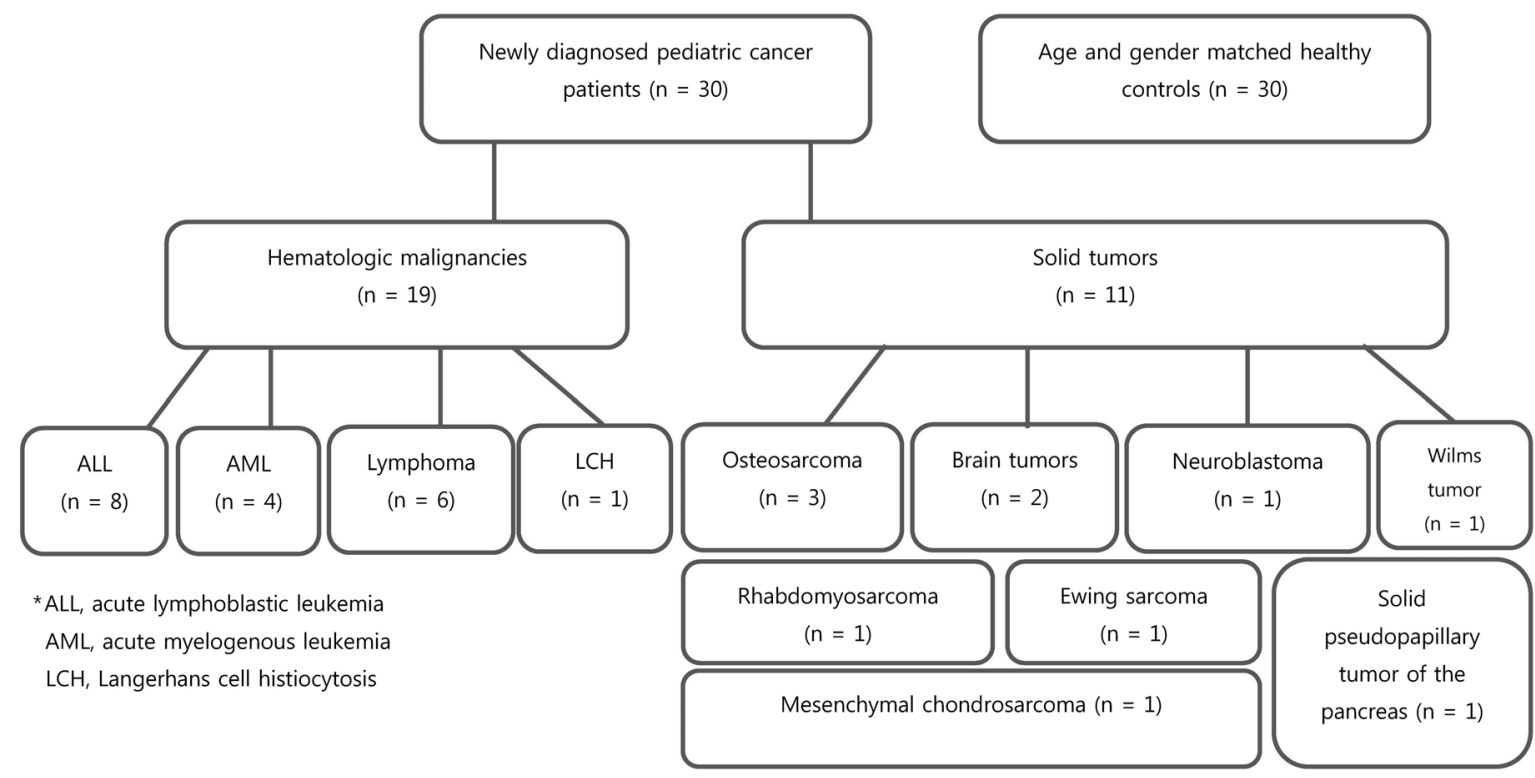

Fig.1. Study participant flowchart 
Madison, WI, USA). Body composition was quantified based on body tissue absorption of photons that are emitted at two energy levels. Body weight (body mass) was stratified into bone mineral, fat-free mass (FFM), and fat mass (FM) using the enCORE version 13.6 (General Electric Medical systems, Madison, WI, USA). Body fat percentages in the whole body, trunk, and extremities were automatically calculated and expressed as percentages. Each patient underwent DXA scanning for about 15 minutes in supine position without any movement in accordance with the manufacturer's recommendations as described in our previous study [16]. DXA measurements were performed at baseline (before initiating cancer treatment) and 1,6 , and 12 month(s) of chemotherapy in all recruited pediatric cancer patients. DXA was measured once at the first visit in the control group and compared with the baseline values from cancer patients.

\section{Statistics}

SPSS version 22.0 (IBM Corp., Armonk, NY, USA) was used for data analyses. All nonparametric continuous values were expressed as a median (range). The Kruskal-Wallis method was used for nonparametric analysis of continuous variables among the three groups. Wilcoxon paired $t$ tests were used for analyzing the changes in the median BMI $z$ scores and body fat percentages between different time intervals [i.e., baseline and 1 month, 1 and 6 month(s), and 6 and 12 month(s)] in children with pediatric cancer regardless of cancer group. Multiple regression analyses were used to evaluate factors affecting body fat composition of the subjects. Generalized estimation equation (GEE) analyses were used to show the trends of body composition changes after short- and long-term follow up. The level of significance was set at $P<0.05$.

\section{Ethics statement}

This study was approved by the Institutional Review Board of the Seoul National University Bundang Hospital (IRB No. B-1208/168-006). Informed consent was obtained from all study subjects and/or their parents.

\section{RESULTS}

\section{Patient characteristics}

The clinical features of the pediatric cancer patients (mean age, $10.9 \pm 3.8 \mathrm{yrs}$ ) and the healthy controls are listed in Table 1. There were no significant differences in demographic parameters, such as age and sex, at baseline among the three groups (i.e., hematologic malignancies, solid tumors, and healthy control groups). Anthropometric parameters (i.e., weight, height, BMI, AC, and $z$ scores of weight, height and BMI) at baseline were also not different among the three groups (Table 1).

\section{Body compositions at baseline}

Comparisons of body composition parameters, measured by DXA, among the hematologic malignancy, solid tumor, and control groups at baseline are shown in Table 2. The leg FFM was different among the three groups $(P=0.011$; Table 2). However, there were no other differences in FFM, FM, or fat percentage among groups.

Changes in weight for age (WFA) $z$ scores and BMl $z$ scores

There were no significant changes in WFA $z$ scores between the different time intervals (i.e., baseline and 1 month, 1-6 month(s), and 6-12 months) in each pediatric cancer group during the first year of cancer treatment (Table 3 ).

The initial median BMI $z$ score of -0.31 (range: $-1.85-1.85$ ) at initial diagnosis increased to $0.04(-1.74-2.39)$ after 1 year of cancer treatment; however, this change was not statistically significant $(P=0.523)$. There were also no significant changes in BMl $z$ scores between the different time intervals in each pediatric cancer group during the first year of cancer treatment (Table 4).

\section{Changes in body composition}

Although the total body mass did not change significantly during the first month of cancer treatment $(P=0.304)$, the total median FFM significantly decreased from $27.4 \mathrm{~kg}$ (range, 11.5 - $53.5 \mathrm{~kg})$ to $26.9 \mathrm{~kg}$ (14.4- $50.6 \mathrm{~kg}, P=0.008)$. The total FFM

Table 1. Clinical features of childhood cancer patients and healthy controls at baseline

\begin{tabular}{|c|c|c|c|c|c|c|c|}
\hline \multirow[b]{2}{*}{ Variable } & \multicolumn{3}{|c|}{ Total $(n=60)$} & \multirow[b]{2}{*}{$P$-value ${ }^{\mathrm{a}}$} & \multirow[b]{2}{*}{$P$-value ${ }^{\mathrm{b}}$} & \multirow[b]{2}{*}{$P$-value ${ }^{c}$} & \multirow[b]{2}{*}{$P$-value } \\
\hline & $\begin{array}{l}\text { Controls } \\
(n=30)\end{array}$ & $\begin{array}{l}\text { Hematologic malignancies } \\
\qquad(\mathrm{n}=19)\end{array}$ & $\begin{array}{l}\text { Solid tumors } \\
\quad(n=11)\end{array}$ & & & & \\
\hline Sex (boys : girls) & $22: 8$ & $14: 5$ & $7: 4$ & 0.607 & 0.979 & 0.653 & 0.682 \\
\hline Age (yrs) & $12.3(6.3-17.2)^{*}$ & $10.9(3.8-17.4)$ & $11.5(5.9-17.4)$ & 0.089 & $0.042^{+}$ & 0.695 & 0.103 \\
\hline Tanner stage [stage 1 5] & $15 / 3 / 5 / 2 / 5$ & $11 / 3 / 2 / 1 / 2$ & $4 / 0 / 3 / 1 / 3$ & 0.463 & - & - & - \\
\hline Weight (kg) & $43.5(26.0-65.0)$ & $32.4(14.9-66.7)$ & $42.9(19.3-63.8)$ & 0.171 & 0.048 & 0.805 & 0.445 \\
\hline Weight $z$ score & $0.24(-2.02-1.92)$ & $0.27(-1.12-1.99)$ & $-0.17(-0.97-1.62)$ & 0.518 & 0.720 & 0.183 & 0.735 \\
\hline Height $(\mathrm{cm})$ & $153.5(119.0-180.0)$ & $141.7(97.2-171.2)$ & $162.9(113.2-178.9)$ & 0.086 & 0.018 & 0.965 & 0.134 \\
\hline Height $z$ score & $0.64(-0.18-2.33)$ & $0.50(-0.07-1.98)$ & $0.73(-0.61-1.80)$ & 0.411 & 0.196 & 0.896 & 0.395 \\
\hline BMI $\left(\mathrm{kg} / \mathrm{m}^{2}\right)$ & $19.6(15.5-24.6)$ & $17.1(15.0-25.2)$ & $17.7(13.9-22.8)$ & 0.348 & 0.255 & 0.226 & 0.933 \\
\hline BMI $z$ score & $-0.01(-2.26-1.57)$ & $-0.22(-1.23-1.85)$ & $-0.42(-1.85-1.47)$ & 0.340 & 0.790 & 0.183 & 0.200 \\
\hline$A C(\mathrm{~cm})$ & $70.3(61.5-83.5)$ & $66.9(47.0-82.0)$ & $66.5(53.0-81.5)$ & 0.387 & 0.075 & 0.400 & 0.604 \\
\hline
\end{tabular}

* Values are expressed as median (range).

${ }^{\dagger} P$-values $<0.05$ were considered statistically significant.

${ }^{\mathrm{a}} \mathrm{C}-\mathrm{H}-\mathrm{S} ;{ }^{\mathrm{b}} \mathrm{C}-\mathrm{H} ;{ }^{\mathrm{c}} \mathrm{C}-\mathrm{S} ;{ }^{\mathrm{d}} \mathrm{H}-\mathrm{S}$

Nonparametric analysis was conducted using the chi-squared test for numeric variables and the Mann-Whitney $\mathrm{U}$ test $(\mathrm{C}-\mathrm{H}, \mathrm{C}-\mathrm{S}, \mathrm{H}-\mathrm{S})$ and $\mathrm{Kruskal}-\mathrm{Wallis}$ method $(\mathrm{C}-\mathrm{H}-\mathrm{S})$ for continuous variables.

$\mathrm{C}$, controls; $\mathrm{H}$, hematologic malignancies; S, solid tumors; $\mathrm{AC}$, abdominal circumference; BMl, body mass index. 
Table 2. Comparison of body composition according to the pediatric cancer type at baseline

\begin{tabular}{|c|c|c|c|c|}
\hline \multirow[b]{2}{*}{ Variable } & \multicolumn{3}{|c|}{ Total $(n=60)$} & \multirow[b]{2}{*}{$P$-value* } \\
\hline & $\begin{array}{c}\text { Controls } \\
(\mathrm{n}=30)\end{array}$ & $\begin{array}{l}\text { Hematologic malignancies } \\
\qquad(\mathrm{n}=19)\end{array}$ & $\begin{array}{l}\text { Solid tumors } \\
\quad(n=11)\end{array}$ & \\
\hline Total mass, legs (kg) & $15.4(8.9-23.4)$ & $10.9(3.3-23.6)$ & $14.7(5.6-21.6)$ & 0.050 \\
\hline Lean mass, legs (kg) & $10.2(5.2-17.7)$ & $7.6(2.3-18.2)$ & $10.2(4.6-18.4)$ & $0.011^{*}$ \\
\hline Fat mass, legs $(\mathrm{kg})$ & $4.4(1.4-7.8)$ & $3.1(0.9-8.3)$ & $3.4(0.8-6.7)$ & 0.266 \\
\hline Fat percentage, legs (\%) & $29.4(9.0-42.9)$ & $27.3(15.9-47.4)$ & $27.5(8.4-45.8)$ & 0.707 \\
\hline Total mass, trunk $(\mathrm{kg})$ & $19.4(11.5-29.0)$ & $14.7(7.0-30.0)$ & $19.1(8.7-30.1)$ & 0.274 \\
\hline Lean mass, trunk $(\mathrm{kg})$ & $14.2(7.4-23.1)$ & $11.6(5.9-23.8)$ & $14.8(7.9-24.9)$ & 0.212 \\
\hline Fat mass, trunk $(\mathrm{kg})$ & $4.2(1.3-9.4)$ & $2.9(1.1-10.0)$ & $3.6(0.6-9.3)$ & 0.594 \\
\hline Fat percentage, trunk (\%) & $25.0(6.3-40.3)$ & $18.4(10.6-40.9)$ & $22.1(4.4-43.7)$ & 0.633 \\
\hline Body mass, total $(\mathrm{kg})$ & $43.4(26.1-64.7)$ & $32.3(14.6-65.1)$ & $41.5(18.5-62.5)$ & 0.115 \\
\hline Lean mass, total $(\mathrm{kg})$ & $29.8(16.5-50.7)$ & $24.2(11.5-51.2)$ & $30.8(16.0-53.5)$ & 0.080 \\
\hline Fat mass, total $(\mathrm{kg})$ & $10.4(3.3-20.0)$ & $7.0(2.6-21.5)$ & $8.4(1.8-18.8)$ & 0.549 \\
\hline Fat percentage, total (\%) & $26.1(7.3-36.9)$ & $20.0(12.6-41.7)$ & $24.0(5.9-42.0)$ & 0.794 \\
\hline
\end{tabular}

* $P$-values $<0.05$ were considered statistically significant.

${ }^{\dagger}$ Values are all expressed as median (range).

Nonparametric analysis was conducted using the Kruskal-Wallis method for continuous variables.

Table 3. Wilcoxon paired $t$ tests for changes in weight $z$ score between two time intervals in pediatric cancer patients

\begin{tabular}{|c|c|c|c|c|}
\hline Time interval & Weight $z$ score $_{\text {initial }}$ & Weight $z$ score $_{\text {follow-up }}$ & $\Delta$ Weight $z$ score ${ }_{\text {(initial } \rightarrow \text { follow-up) }}$ & $P$-value* \\
\hline \multicolumn{5}{|l|}{ Total $(n=30)$} \\
\hline Baseline-1 month & $0.13(-1.12-1.88)^{\dagger}$ & $-0.22(-1.69-2.00)$ & $0.05(-0.10-0.20)$ & 0.304 \\
\hline $1-6$ months & $-0.22(-1.69-2.00)$ & $-0.19(-1.51-2.11)$ & $0.03(-0.16-0.23)$ & 0.496 \\
\hline 6-12 months & $-0.19(-1.51-2.11)$ & $-0.18(-1.50-2.22)$ & $-0.05(-0.15-0.08)$ & 0.694 \\
\hline \multicolumn{5}{|c|}{ Hematologic malignancies $(n=19)$} \\
\hline Baseline-1 month & $0.27(-1.12-1.88)$ & $-0.01(-1.69-2.00)$ & $0.02(-0.20-0.23)$ & 0.472 \\
\hline 1-6 months & $-0.01(-1.69-2.00)$ & $-0.02(-1.51-2.11)$ & $0.00(-0.26-0.27)$ & 0.647 \\
\hline 6-12 months & $-0.02(-1.51-2.11)$ & $0.22(-1.50-2.22)$ & $-0.06(-0.20-0.09)$ & 0.378 \\
\hline \multicolumn{5}{|l|}{ Solid tumors $(n=11)$} \\
\hline Baseline-1 month & $-0.17(-0.97-1.62)$ & $-0.25(-1.15-1.67)$ & $0.10(-0.12-0.32)$ & 0.328 \\
\hline $1-6$ months & $-0.25(-1.15-1.67)$ & $-0.30(-1.31-1.39)$ & $0.08(-0.27-0.42)$ & 0.657 \\
\hline 6-12 months & $-0.30(-1.31-1.39)$ & $-0.47(-1.27-1.48)$ & $-0.00(-0.21-0.20)$ & 0.533 \\
\hline
\end{tabular}

* $P$-values $<0.05$ were considered statistically significant.

${ }^{\dagger}$ Values are expressed as median (range).

$P$-values were analyzed using Wilcoxon paired $t$ test.

Table 4. Wilcoxon paired $t$ tests for changes in the BMl $z$ score between two time intervals in pediatric cancer patients

\begin{tabular}{|c|c|c|c|c|}
\hline Time interval & BMI $z$ score initial & BMI $z$ scorefollow-up & $\triangle \mathrm{BMI} z$ score (initial $\rightarrow$ follow-up) & $P$-value* \\
\hline \multicolumn{5}{|l|}{ Total $(n=30)$} \\
\hline Baseline-1 month & $-0.31(-1.85-1.85)^{\dagger}$ & $0.09(-2.00-2.19$ & $-0.10(-0.96-1.72)$ & 0.855 \\
\hline $1-6$ months & $0.09(-2.00-2.19)$ & $-0.20(-1.99-2.17)$ & $-0.06(-1.49-2.30)$ & 0.817 \\
\hline 6-12 months & $-0.20(-1.99-2.17)$ & $0.04(-1.74-2.39)$ & $0.07(-0.70-1.06)$ & 0.362 \\
\hline \multicolumn{5}{|c|}{ Hematologic malignancies $(n=19)$} \\
\hline Baseline-1 month & $-0.22(-1.23-1.85)$ & $0.57(-2.00-2.19)$ & $-0.09(-0.96-1.72)$ & 0.533 \\
\hline $1-6$ months & $0.57(-2.00-2.19)$ & $0.11(-1.40-2.17)$ & $-0.06(-1.49-2.30)$ & 0.783 \\
\hline 6-12 months & $0.11(-1.40-2.17)$ & $0.43(-1.46-2.39)$ & $0.13(-0.70-0.73)$ & 0.229 \\
\hline \multicolumn{5}{|l|}{ Solid tumors $(n=11)$} \\
\hline Baseline-1 month & $-0.42(-1.85-1.47)$ & $-0.82(-1.99-1.63)$ & $-0.14(-0.73-0.66)$ & 0.431 \\
\hline $1-6$ months & $-0.82(-1.99-1.63)$ & $-0.70(-1.99-1.29)$ & $-0.22(-0.94-1.10)$ & 1.000 \\
\hline 6-12 months & $-0.70(-1.99-1.29)$ & $-0.81(-1.74-1.58)$ & $0.14(-0.52-1.06)$ & 0.947 \\
\hline
\end{tabular}

* $P$-values $<0.05$ were considered statistically significant.

${ }^{\dagger}$ Values are expressed as median (range).

$P$-values were analyzed using Wilcoxon paired $t$ test.

BMl: body mass index 


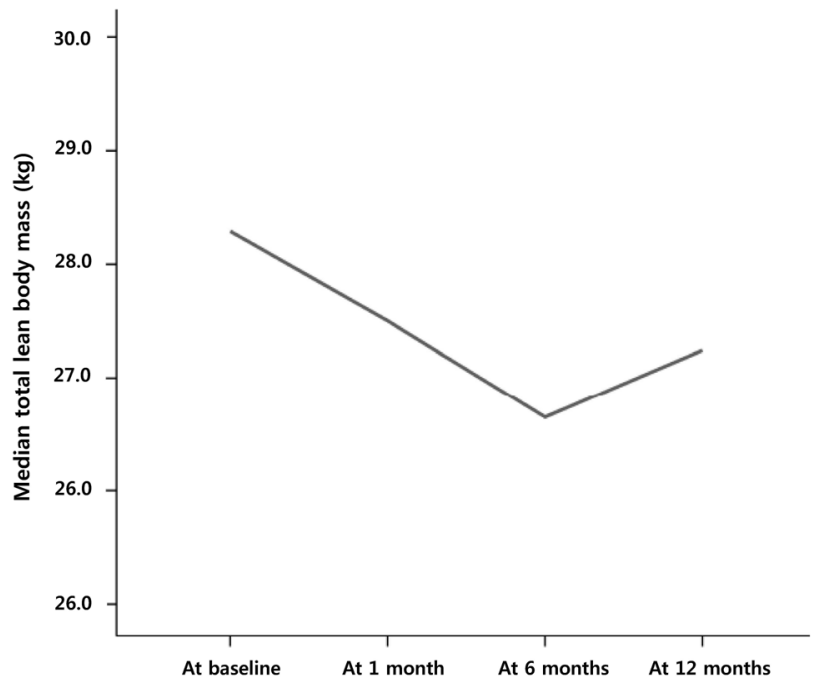

Fig. 2. Changes in the median total fat-free mass in pediatric cancer patients. A significant decrease during the first month of cancer treatment followed by an increase between 6 and 12 months is shown. No significant changes were observed between 1 month and 6 months.

significantly increased from $26.0 \mathrm{~kg}(12.0-52.4 \mathrm{~kg})$ at 6 months to $27.2 \mathrm{~kg}(13.6-54.1 \mathrm{~kg})$ at 12 months of cancer treatment $(P<0.001$; Fig. 2).

In contrast, the total median FM and body fat percentage increased significantly from $7.2 \mathrm{~kg}(1.8-21.5 \mathrm{~kg})$ to $9.2 \mathrm{~kg}(2.1$ - $21.5 \mathrm{~kg}, P=0.000$; Fig. $3 \mathrm{~A})$ and $21.4 \%(5.9-42.0 \%)$ to $25.8 \%$ (9.5-43.3\%, $P=0.002$; Fig. 3B), respectively, during the first month. However, there were no significant changes in the total FM or fat percentages between time intervals (i.e., 1 to 6 months and 6 to 12 months) after 1 month of cancer treatment (all $P>0.05$; Fig. $3 \mathrm{~A}$ and $3 \mathrm{~B}$ ). There were significant changes in the fat percentage of the extremities and trunk during the first month of cancer therapy $(P<0.001$ and $P<$ 0.001 , respectively).

Changes in body fat percentage in each pediatric cancer group The median body fat percentage in children with hematologic malignancies significantly increased from $20.0 \%$ (12.6-41.7\%) to $27.4 \%$ (14.5 - 43.3\%) during the first month of cancer treatment $(P=0.003$; Table 4). However, there were no significant changes in body fat percentage between 1 and 6 month(s) and 6 and
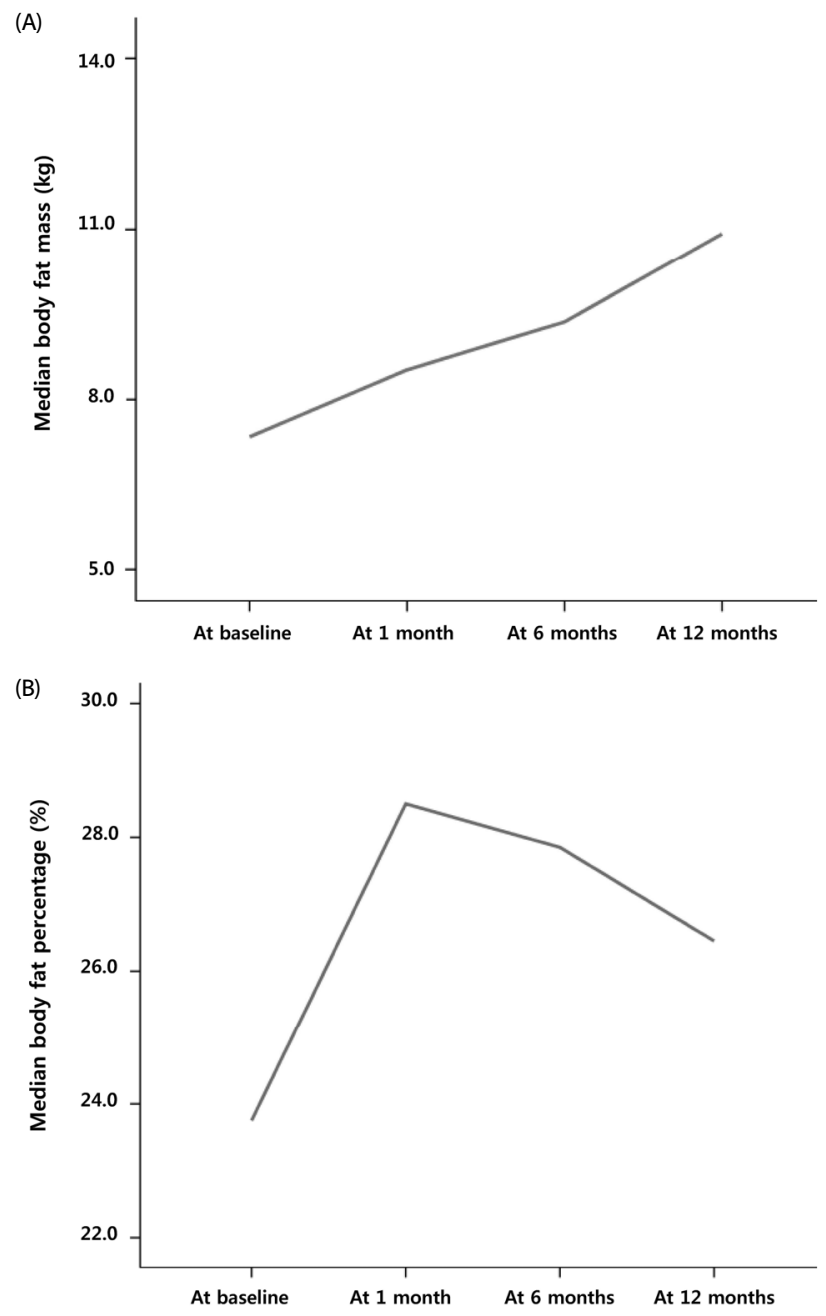

Fig. 3. Changes in the median total fat mass (A) and body fat percentage (B) in pediatric cancer patients. A significant increase during the first month of cancer treatment followed by no changes up to 12 months is shown.

12 month (s) after initiating cancer treatment $(P=0.449$ and $P=0.196$, respectively; Table 5 ).

In children with solid tumors, significant changes in body fat percentage were also observed between baseline and 1 month of follow-up ( $P=0.007$; Table 4 ), although no significant changes

Table 5. Wilcoxon paired $t$ tests for changes in body fat percentages between two time intervals in pediatric cancer patients

\begin{tabular}{|c|c|c|c|c|}
\hline Time interval & Body fat percentage $\mathrm{e}_{\text {initial }}(\%)$ & Body fat percentage follow-up (\%) & $\triangle$ Body fat percentage (initial $\rightarrow$ follow-up) & $P$-value* \\
\hline \multicolumn{5}{|l|}{ Hematologic malignancies } \\
\hline Baseline-1 month & $20.0(12.6-41.7)^{\dagger}$ & $27.4(14.5-43.3)$ & $5.0(-1.8-12.2)$ & $0.003^{*}$ \\
\hline 1-6 months & $27.4(14.5-43.3)$ & $28.1(12.6-41.4)$ & $-0.4(-5.8-4.8)$ & 0.449 \\
\hline 6-12 months & $28.1(12.6-41.4)$ & $26.6(12.0-45.9)$ & $1.6(-12.3-7.1)$ & 0.196 \\
\hline \multicolumn{5}{|l|}{ Solid tumors } \\
\hline Baseline-1 month & $24.0(5.9-42.0)$ & $25.2(9.5-42.4)$ & $1.1(-0.1-2.5)$ & $0.007^{*}$ \\
\hline $1-6$ months & $25.2(9.5-42.4)$ & $23.6(11.2-45.0)$ & $2.2(-5.2-5.0)$ & 0.192 \\
\hline 6-12 months & $23.6(11.2-45.0)$ & $24.5(11.5-37.5)$ & $-1.4(-4.1-7.5)$ & 0.407 \\
\hline
\end{tabular}

* $P$-values $<0.05$ were considered statistically significant.

${ }^{\dagger}$ Values are expressed as median (range).

$P$-values were analyzed by Wilcoxon paired $t$ test. 


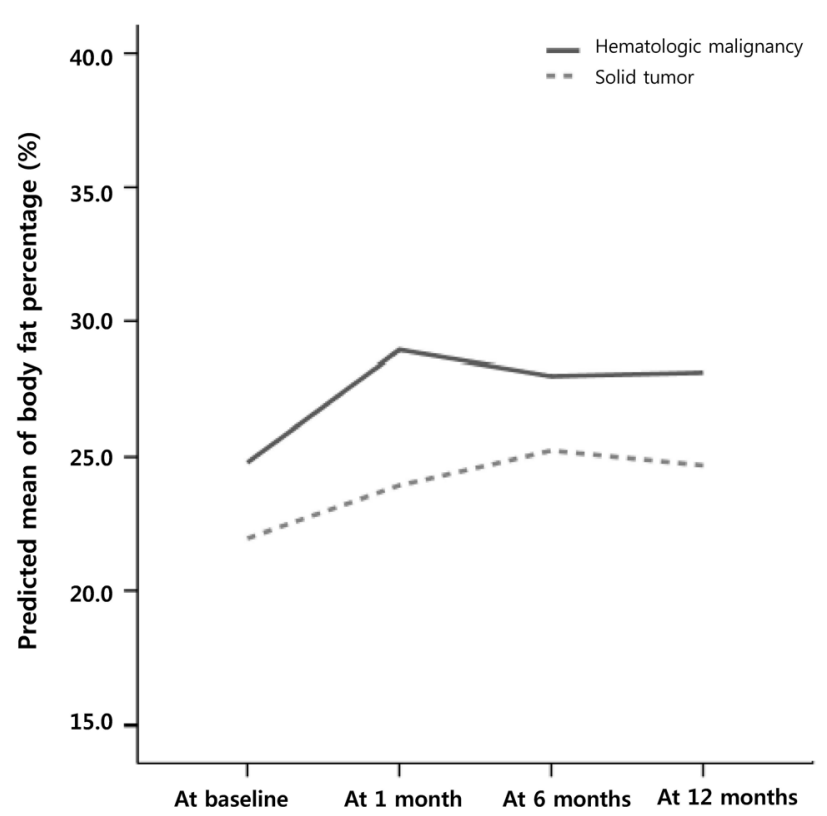

Fig. 4. Generalized estimation equation analysis of trends for changes in body fat percentage in each pediatric cancer group. A significant upward trend for changes in body fat percentage during the first year, especially the first month of cancer treatment in children with hematologic malignancies, but not in those with solid tumors, is shown.

Table 6. Generalized estimation equation analysis of the trends for changes in body fat percentages during the first year according to pediatric cancer group

\begin{tabular}{lcccr}
\hline \multicolumn{1}{c}{ Intervals } & Mean & SE & $95 \%$ Wald Cl & $P$-value \\
\hline $\begin{array}{l}\text { Hematologic malignancies } \\
\text { Baseline-1 month }\end{array}$ & 4.13 & 1.04 & $(2.11-6.18)$ & $<0.001$ \\
Baseline-6 months & 3.20 & 1.05 & $(1.15-5.26)$ & 0.002 \\
Baseline-12 months & 3.34 & 1.94 & $(-0.47-7.15)$ & 0.006 \\
Solid tumors & & & & \\
Baseline-1 month & -2.16 & 1.31 & $(-4.72-0.40)$ & 0.098 \\
Baseline-6 months & 0.08 & 1.53 & $(-2.93-3.09)$ & 0.958 \\
Baseline-12 months & -0.61 & 2.84 & $(-6.18-4.97)$ & 0.831 \\
\hline
\end{tabular}

* Means are the average decrement or increment across time intervals.

$\mathrm{SE}$, standard error; $\mathrm{Cl}$, confidence interval.

in body fat percentage were observed between 1 and 6 month(s) and 6 and 12 months of follow-up $(P=0.192$ and $P$ $=0.402$, respectively; Table 5 ).

Trends in body fat percentage in each pediatric cancer group

The trends for changes in mean body fat percentage between baseline and 1, 6, and 12 month(s) after initiating cancer treatment in each group pediatric cancer group are shown in Fig. 3. In children with hematologic malignancies, there was a significant upward trend in body fat percentage between baseline and at each follow-up period during the first year, especially the first month, of cancer treatment (Fig. 4 \& Table 6). However, there were no significant upward trends for changes in body fat percentage during the first year of treatment in children with solid tumors (Fig. 4 \& Table 6).

\section{DISCUSSION}

In the present study, we first prospectively evaluated the trends of body composition changes during the first year of cancer treatment in pediatric cancer patients. At baseline, there were no differences in anthropometric (i.e., weight, height, BMI z scores, and AC) and DXA-based body composition (i.e., FFM, FM, and body fat percentage) measurements among the 3 groups (i.e., hematologic malignancies, solid tumors, and healthy control group). However, a decrease in the total FFM and no change in the body weight were observed during the first month of follow-up after initiating cancer treatment. The FFM recovered during the interval between 6 and 12 months, while the total FM and body fat percentage increased significantly during the first month without significant changes after 1 to 12 month(s). This rapid increase in body fat during the first month of cancer therapy was obvious in both the extremities and trunks of our study subjects.

According to previous studies, most cancer patients undergoing cancer therapy experience diverse body composition changes during the disease course. Breast and prostate cancer patients may gain body fat and lose lean body mass (LBM), while lung and colon cancer patients may have an accelerated loss of LBM [9]. In previous studies regarding body composition changes, no significant net body weight or BMl changes during chemotherapy were observed in breast cancer patients because the LBM mass decreased while the FM increased or vice versa $[11,12]$. Even in our study of pediatric cancer patients, the decrease in LBM and increase in FM and body fat percentage during the first month occurred without any significant body weight or BMl changes. These findings may suggest that body composition measurements focused on the change of each body compartment (e.g., FM and FFM) rather than changes in body weight or BMI based on anthropometric measurement may provide more accurate information about body composition changes during cancer treatment in children.

In the present study, a significant decrease in LBM was observed during the first month, which later recovered between 6 and 12 months, while body fat dramatically increased during the first month without any additional significant increase in body fat afterwards. There have been several studies regarding short- and long-term body composition changes in pediatric cancer patients during cancer treatment [2,10,13-15]. According to a prospective cohort study by Brinksma et al. [15], body weight, BMl, and FM increased during the first 3 months of follow-up after initiating treatment. However, FFM, which was already low at diagnosis, remained low during the disease course. These findings also suggest that body composition changes, mainly those related to body fat, in pediatric cancer patients develop particularly in the early stage of cancer treatment as well as cancer-related cachexia [19]. There was no relationship between energy intake or corticosteroid therapy and the increase in BMl or body fat, and the authors suggested that tube feeding and decreased physical activity might be associated with increases in BMI and body fat [15]. However, in our study, the increase in body fat occurred mainly during the first month, and no patients received nutritional support via tube feeding. Therefore, further explanations for this 
phenomenon of body fat change in children with cancer are required and possible explanations for this change in pediatric cancer patients may be the combination of several factors such as imbalanced diet during the initial period of cancer therapy, immobilization or decreased physical activity, and intensive chemotherapy in conjunction with corticosteroids, all of which may gradually resolve during the second half year after initiating cancer treatment.

In the present study, we also evaluated and compared the differences in short- and long-term body composition changes over time between patients with hematologic malignancies and solid tumors. A significant increase in body fat was observed in both groups during the first month of cancer treatment, but not afterwards. When additional statistical analysis was conducted using GEE, a significant upward trend for body fat changes was observed during the first year of cancer treatment in children with hematologic malignancies, but not in those with solid tumors. Early changes of increased adiposity may be related to high calorie diet, immobilization, and therapeutic regimens including corticosteroids, especially in children with hematologic malignancies. However, emetogenic chemotherapy agents administered in children with solid tumors lead to adverse effects that may countervail an increase in adiposity during the early stages, such as intense vomiting and poor oral intake.

As described in our study, underlying cancers with different treatment modalities seem to make differences between different pediatric cancer groups. According to a previous report in 15 children with hematologic malignancies, a significant increase in the BMI $z$ scores of cancer patients was observed at the 1-year follow-up, at 6-month intervals, compared to healthy controls [14]. The increase in FM and LBM was both higher in children with hematologic malignancies than healthy controls in this previous study; however, the increase in body fat percentage and the decrease in LBM percentage were relatively higher in pediatric cancer patients compared to those of healthy controls [14]. However, according to a study in children and young adults with solid tumors (i.e., Ewing sarcoma and osteosarcoma), body weight and BMI decreased dramatically during treatment and then recovered during the follow-up until 24 months [13]. These findings suggested that there is a risk of undernutrition during multimodality cancer therapy for children with solid tumors, but they will recover to normal after active anti-cancer therapy [13]. In another study that evaluated children with hematologic malignancies and solid tumors, weight changes (weight gain or loss) of $>5 \%$ were common in both cancer groups within the first 3 months, whereas weight gains were more prevalent in both groups between 3 to 12 months [15]. According to these limited findings, further research regarding heterogeneous body composition changes in pediatric cancer patients based on their underlying malignancies is warranted.

Based on previous reports, body composition changes, such as a tendency to gain body fat, especially in the trunk, and reduced LBM, may result in overweight or obesity-related complications after the cessation of cancer therapy and in later life [10,20-23]. According to a report from the Children's Oncology Group, the beginning of maintenance therapy was suggested to be the best time to intervene with nutritional and behavioral interventions to reduce the risk for obesity in pediatric cancer patients [22]. However, based on the results from our study, individualized dietary and behavioral strategies along with cancer therapy starting at a very early stage of cancer treatment and continuing through the disease course might be more appropriate to prevent excessive fat gain and loss of LBM during cancer treatment and to improve outcomes later in life in pediatric cancer patients.

Our study has some limitations. First, although it is a prospective cohort study, this study was conducted in a small study sample with 30 cancer patients and 30 controls. Second, a variety of underlying cancers were included, which were classified as two main cancer groups of smaller numbers. Therefore, statistical analysis was performed using nonparametric statistical analysis to overcome these limitations. Third, because there were some barriers in obtaining data on energy intake of the subjects, the explanations for changes in body composition are to some extent limited in this study, requiring further studies.

In conclusion, significant changes in body composition were observed during the first year of cancer treatment, especially during the first month after initiating treatment. A rapid increase in body fat and a decrease in LBM, particularly in children with hematologic malignancies, were observed. Therefore, individualized nutritional strategies based on body composition changes and body fat gaining according to the underlying cancer type are needed during the early period of cancer treatment in children for better clinical outcomes.

\section{ACKNOWLEDGEMENTS}

The authors thank the participating pediatric cancer patients and their families. We also thank Dr. JB Lee and the Division of Statistics at the Medical Research Collaborating Center, Seoul National University Bundang Hospital for assistance with statistical analysis.

\section{CONFLICT OF INTEREST}

The authors declare no potential conflicts of interests.

\section{ORCID}

Hye Ran Yang: https://orcid.org/0000-0002-3423-6922

Hyoung Soo Choi: https://orcid.org/0000-0002-4837-164X

\section{REFERENCES}

1. Collins L, Nayiager T, Doring N, Kennedy C, Webber C, Halton J, Walker S, Sala A, Barr RD. Nutritional status at diagnosis in children with cancer I. An assessment by dietary recall--compared with body mass index and body composition measured by dual energy X-ray absorptiometry. J Pediatr Hematol Oncol 2010;32:e299-303.

2. Brinksma A, Roodbol PF, Sulkers E, de Bont ES, Burgerhof JG, Tamminga RY, Jager-Wittenaar $\mathrm{H}$, Tissing WJ. Finding the right balance: an evaluation of the adequacy of energy and protein intake in childhood cancer patients. Clin Nutr 2015;34:284-90. 
3. Iniesta RR, Paciarotti I, Brougham MF, McKenzie JM, Wilson DC. Effects of pediatric cancer and its treatment on nutritional status: a systematic review. Nutr Rev 2015;73:276-95.

4. Sala A, Rossi E, Antillon F, Molina AL, de Maselli T, Bonilla M, Hernandez A, Ortiz R, Pacheco C, Nieves R, Navarrete M, Barrantes $M$, Pencharz P, Valsecchi MG, Barr R. Nutritional status at diagnosis is related to clinical outcomes in children and adolescents with cancer: a perspective from Central America. Eur J Cancer 2012;48:243-52.

5. Murphy AJ, White M, Davies PS. Body composition of children with cancer. Am J Clin Nutr 2010;92:55-60.

6. Brinksma A, Huizinga G, Sulkers E, Kamps W, Roodbol P, Tissing W. Malnutrition in childhood cancer patients: a review on its prevalence and possible causes. Crit Rev Oncol Hematol 2012;83: 249-75.

7. Tan SY, Poh BK, Nadrah MH, Jannah NA, Rahman J, Ismail MN. Nutritional status and dietary intake of children with acute leukaemia during induction or consolidation chemotherapy. J Hum Nutr Diet 2013;26 Suppl 1:23-33.

8. Butturini AM, Dorey FJ, Lange BJ, Henry DW, Gaynon PS, Fu C, Franklin J, Siegel SE, Seibel NL, Rogers PC, Sather H, Trigg M, Bleyer WA, Carroll WL. Obesity and outcome in pediatric acute lymphoblastic leukemia. J Clin Oncol 2007;25:2063-9.

9. Di Sebastiano KM, Mourtzakis M. A critical evaluation of body composition modalities used to assess adipose and skeletal muscle tissue in cancer. Appl Physiol Nutr Metab 2012;37:811-21.

10. Murphy AJ, White M, Elliott SA, Lockwood L, Hallahan A, Davies PS. Body composition of children with cancer during treatment and in survivorship. Am J Clin Nutr 2015;102:891-6.

11. Halpern-Silveira D, Susin LR, Borges LR, Paiva Sl, Assunção MC, Gonzalez MC. Body weight and fat-free mass changes in a cohort of patients receiving chemotherapy. Support Care Cancer 2010;18:617-25.

12. Sheean PM, Hoskins K, Stolley M. Body composition changes in females treated for breast cancer: a review of the evidence. Breast Cancer Res Treat 2012;135:663-80.

13. Tenardi RD, Frühwald MC, Jürgens $H$, Hertroijs $D$, Bauer J. Nutritional status of children and young adults with Ewing sarcoma or osteosarcoma at diagnosis and during multimodality therapy. Pediatr Blood Cancer 2012;59:621-6.

14. Fuemmeler BF, Pendzich MK, Clark K, Lovelady C, Rosoff $P$, Blatt J, Demark-Wahnefried W. Diet, physical activity, and body composition changes during the first year of treatment for childhood acute leukemia and lymphoma. J Pediatr Hematol Oncol 2013;35:437-43.

15. Brinksma A, Roodbol PF, Sulkers E, Kamps WA, de Bont ES, Boot AM, Burgerhof JG, Tamminga RY, Tissing WJ. Changes in nutritional status in childhood cancer patients: a prospective cohort study. Clin Nutr 2015;34:66-73.

16. Choi HS, Chang E, Lee EH, Yang HR. Changes in bone health during the first year of cancer treatment in children. J Clin Densitom 2017;20:25-31.

17. Harrington DM, Staiano AE, Broyles ST, Gupta AK, Katzmarzyk PT. Waist circumference measurement site does not affect relationships with visceral adiposity and cardiometabolic risk factors in children. Pediatr Obes 2013;8:199-206.

18. Kim JH, Yun S, Hwang SS, Shim JO, Chae HW, Lee YJ, Lee JH, Kim SC, Lim D, Yang SW, Oh K, Moon JS; Committee for the Development of Growth Standards for Korean Children and Adolescents; Committee for School Health and Public Health Statistics, the Korean Pediatric Society; Division of Health and Nutrition Survey, Korea Centers for Disease Control and Prevention. The 2017 Korean National Growth Charts for children and adolescents: development, improvement, and prospects. Korean J Pediatr 2018;61:135-49.

19. Ladas E, Sacks N, Meacham L, Henry D, Enriquez L, Lowry G, Hawkes R, Dadd G, Rogers P. A multidisciplinary review of nutrition considerations in the pediatric oncology population: a perspective from children's oncology group. Nutr Clin Pract 2005;20:377-93.

20. Jarfelt M, Lannering B, Bosaeus I, Johannsson G, Bjarnason R. Body composition in young adult survivors of childhood acute lymphoblastic leukaemia. Eur J Endocrinol 2005;153:81-9.

21. Barr R, Nayiager T, Gordon C, Marriott C, Athale U. Body composition and bone health in long-term survivors of acute lymphoblastic leukaemia in childhood and adolescence: the protocol for a cross-sectional cohort study. BMJ Open 2015;5:e06191.

22. Withycombe JS, Post-White JE, Meza JL, Hawks RG, Smith LM, Sacks $\mathrm{N}$, Seibel NL. Weight patterns in children with higher risk ALL: a report from the Children's Oncology Group (COG) for CCG 1961. Pediatr Blood Cancer 2009;53:1249-54.

23. Shin DW, Cho B, Kim SY, Jung JH, Park JH. Management of cancer survivors in clinical and public health perspectives: current status and future challenges in Korea. J Korean Med Sci 2013;28:651-7. 